\title{
Developing a Calculation Tool for Embodied Energy in the Conceptual Design Phase
}

\author{
Sara Maassarani \\ Ph.D. candidate \\ Faculty of Architectural \\ Engineering \\ Beirut Arab University
}

\author{
Mostafa R. A. Khalifa \\ Assistant Professor \\ Faculty of Architectural \\ Engineering \\ Beirut Arab University
}

\author{
Nabil Mohareb \\ Associate Professor \\ Faculty of Architectural \\ Engineering \\ Beirut Arab University
}

\begin{abstract}
Energy performance of a building is one of the main features to be assessed and optimized in sustainable building designs. While progress in reducing the operating energy is being achieved, the embodied energy remains somewhat high. The building industry is currently using around $40-50 \%$ of global raw material that is responsible for the $40-45 \%$ of the total worldwide carbon dioxide emissions.
\end{abstract}

Embodied energy and carbon calculations are rather complex since they are related to different combinations of material whether in the structure or the finishing material. Reducing the embodied energy can be done by either varying the structural design, increasing the service of the building, or using recycled material. Conventionally, these calculations are not strictly part of the designer's work during the conceptual design phase; hence, if done, they are calculated during the design evaluation phase when the design decisions have been already set, and change in design decisions is not easy. Under most circumstances, the environmental impact assessment of designs was performed by sustainability consultants who may not be present in many projects. It is better to bring the embodied energy calculations to the conceptual design phase so both the architect and the structural engineer can make informed design decisions for a more sustainable building. Many organizations are using in-house tools to make these calculations, but the tools used are not flexible enough to be adopted by a wide variety of users. A better way is to use the functionality of Building Information Modelling (BIM) software by developing plug-in tools that are simple to use in early stages of conceptual design.

This paper explores two existing plug-ins that function with Rhinoceros (Rhino) and Grasshopper (GH) software, where they define a set of parameters to evaluate the embodied energy in the structure of the building. The aim of this paper is to develop a tool that can be used more easily and that adds to the existing parameters to give a more accurate estimation of the building's embodied energy during the conceptual design stage. For this purpose, a comparative analysis will be performed of both plug-ins to determine their best features and to add the missing components concerning the embodied energy of finishing material. The proposed tool will be developed using visual basic scripting language to be used with Rhino and GH. Finally, the prototype will be open sourced for testing and verification while conclusions concerning the limitations and future development opportunities will be discussed.

\section{General Terms}

Programming, Energy Performance, Architectural Design

\section{Keywords}

Embodied energy, embodied carbon, conceptual stage simulation, computational tool, design optimization

\section{INTRODUCTION}

Renewable and non-renewable natural resources are largely exploited by the construction industry and its supporting industries, which is negatively affecting the Earth's environment [1-6]. Construction of buildings consumes large amounts of commercial energy by burning fossil fuel to generate heat and electricity [1]. The exploitation of these resources with limited control is compromising their presence for future generations. In general, the life span of buildings can be classified into several stages, where each stage consumes its share of energy, raw material, and natural resources (Figure 1). Wastage, pollution, and environmental degradation can result from any of these stages once nonsustainable practices are adopted. In fact, Huovila states that buildings account for about $30-40 \%$ of the worldwide energy consumption, therefore the construction industry is responsible for around $40-45 \%$ of total worldwide $\mathrm{CO} 2$ emissions [7]. 


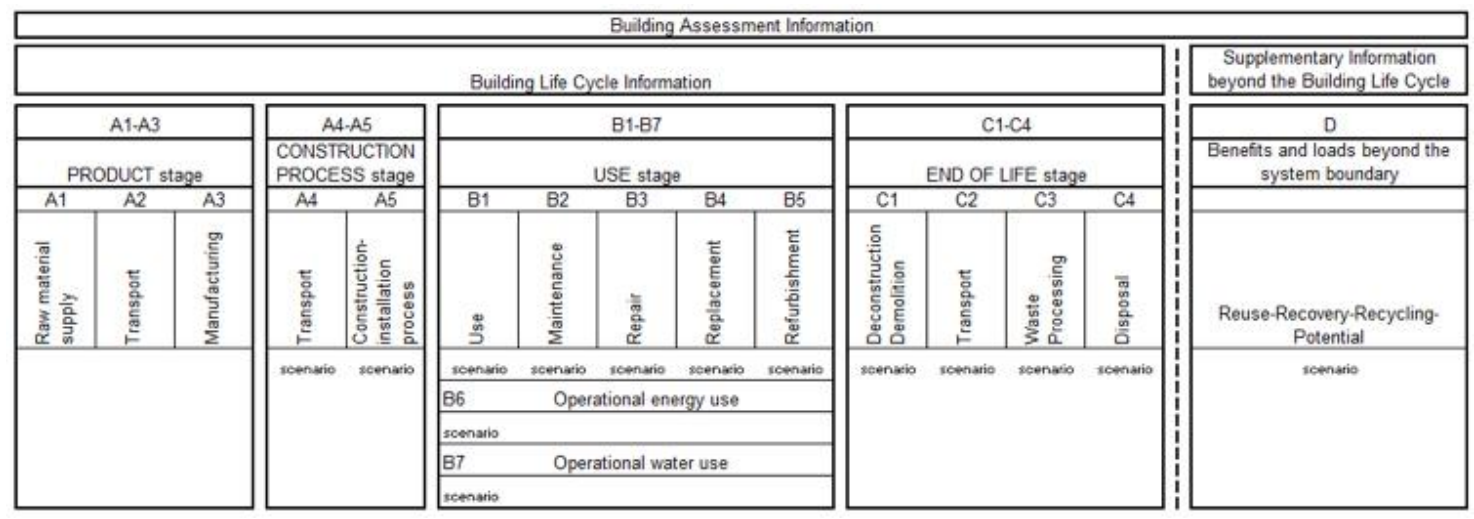

Figure 1. Life cycle stages and modules used in CEN/TC 350 standards such as EN 15804 [8]

\subsection{Green Buildings}

In order to protect the natural resources, it was important to adopt sustainable practices, where sustainability is to manage various environmental resources to be available for present and future generations [21]. The various stages of the building life cycle allow for various methods in preserving natural resources. Mostly, the design stage provides the greatest opportunity to make sustainable decisions that affect the whole life cycle of the building. Studies and simulation at this stage will help use the least resources possible to design a functional building. The studies at this stage aim at designing a building that uses minimum material and reduces the energy demands during its life cycle. Legislations are being developed for the purpose of regulating the building industry to limit carbon emissions related to the use of material in buildings.

\subsection{Embodied energy in buildings}

The life cycle energy of buildings is divided into embodied energy and operating energy $[9,10]$. Embodied Energy (EE) is energy related to building materials during processes of production, on-site construction, final demolition, and disposal where the Embodied Energy is related to the Embodied Carbon (EC) released over the life-cycle of the material [25]. On the other hand, Operation Energy (OE) is related to the energy used for the maintenance of indoor environmental quality by heating, cooling, lighting, and operating appliances. The progress in lowering operating energy has taken the priority since it has a larger impact on the total life cycle energy of buildings. The advances in energy efficient appliances and insulation material has led to a big improvement in the reduction of operating energy, so the attention now shifts to reducing the embodied energy [9-14]. It is important for the designer to improve the performance of buildings by balancing both the operational and embodied energy. However, Langston and Langston claim that calculating and measuring the $\mathrm{OE}$ is easy and simple, while determining EE is more complex [15].

The complexity of computing the EE is due to the unique nature of buildings, multiple functionality, on-site assembly, and long design life $[17,18]$. Also, the data required to make an accurate assessment are difficult to obtain. Moreover, there is a lack of tools that can compute the EE accurately and consistently $[10,16]$. This causes the EE calculations to be performed in late stages of the design phase where changes are rather difficult after all decisions have been made, and modifications could be extensive in order to reach the performance criteria [19].
Some organizations are trying to overcome the lack of tools available for EE calculations by using manual spreadsheet calculations and web-based calculation tools during later stages of the design, which proves to be difficult since these manual tools are complex and require that the designer fully understand the calculations to perform them. Also, in most cases the designers were not involved in the environmental impact assessment of designs, therefore they were not sure about the true amount of carbon reduction achieved [20]. Sustainability consultants who are usually introduced at later stages of the building design were responsible for making these calculations, and the concept of EE calculations is not explained to the designers [20]. Keeping the EE calculations for sustainability consultants relegates the designers' responsibility in minimizing the $\mathrm{EE}$ and prevents them from getting feedback on the actual results achieved once the project is completed. Designers have stated their preference for using automatic EE calculation tools during early stages of a project [20]. Embodied energy calculations must be included in the conceptual design phase so both the architect and the structural engineer can make informed design decisions for a more sustainable building. In addition, a proper tool to simplify these calculations must be available for this purpose.

\subsection{Integrating the embodied energy in the conceptual design stage}

As per the preference of designers, calculations of EE and EC should be simplified from the use of spreadsheets and online tools [20]. A better way is to use the functionality of Building Information Modelling (BIM) software by developing plug-in tools that are simple to use in early stages of conceptual design. The literature review shows that the potential in the study of low embodied energy using BIM software needs further exploration and development [21, 22]. Moreover, the availability of a non-complicated tool would help reduce the costs that a client may not be willing to pay for the EE analysis by making it easy to calculate through the regular design process without the need for a specialist.

This paper aims at developing a computational tool that can be used by designers at the conceptual design stage to calculate and visualize the embodied energy and cost in the façades of the building. In order to define the requirements of the tool, the methodology of the paper starts with a literature review to set the parameters and criteria for the computation of embodied energy. A comparative analysis is performed on two existing tools that calculate the embodied energy in the structure of the building, then a small framework is set by determining a single component (the façades) that can be 
added to the function of the existing tools. The prototype script is tested on a case study and is open sourced for further testing and verification while conclusions concerning the limitations and future development opportunities will be discussed. The proposed tool is developed using Visual Basic scripting language to be used with Rhino and GH having its final output easily incorporated to BIM models. The initial input data will be either added manually by the designer, or imported from Revit as an excel sheet using GH plug-ins like gHowl. The script and algorithms are added on the GH interface using the Visual Basic plug-in for $\mathrm{GH}$. The final results are visualized as an interactive color coded model in Rhino. Any changes in the input will be visualized instantaneously. The results can also be exported as an excel sheet.

1. List of software used:

2. Rhinoceros - Version 5 SR5 (5.5.30717.16015, 07/17/2013)

3. Grasshopper - Version August 27, 2014 Build 0.9.0076

4. Autodesk Revit 2016

5. gHowl_r50 2011-Sep-05

\section{DEVELOPMENT OF THE EMBODIED ENERGY CALCULATION TOOL}

The design process alternates options within a set of variables while testing and simulating the design model until an optimum design is reached. Taking the building energy as an example, an optimized energy performance does not always mean the least EE consumption. Sometimes increasing the embodied energy could decrease the operating energy like with the use of photovoltaics in a design. Therefore, the designer is faced with trade-offs that must be considered while evaluating the overall performance of the building. If provided with a proper computational tool to visualize these variations, the designer will be able to make sustainable decisions more accurately.

\subsection{Adaptability and re-use of a building}

Various methods can be adopted to lower the EE of a building, the main being recycling and reuse of material. But this may not be applicable in many cases and wastage is still possible at the end of life of a building. The solution would be to design buildings that can adapt to a change of function to prolong their use in the future. A building that can undergo changes in services, engineering strategies, aesthetic values, architectural trends, and functions is considered to be adaptable [27]. Improving the adaptability of a structure starts with identifying the key factors that prolong the life of a building. Tool defines these factors into the building's stability system, load bearing capacity, floor to floor height, structural grid size, façades, and installations in addition to the flexibility of voids in the building (Figure 2) [28]. Each of these factors contributes to a certain extent in the life span of a building; hence, they can affect the EE and embodied carbon of building material. These factors can be studied and given various options during early conceptual design stages to choose the best solution that minimizes the embodied energy. The more the details provided in calculating these factors, the more accurate results would be produced.

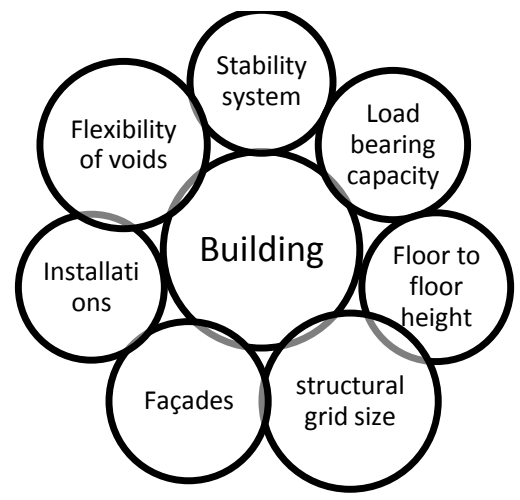

Figure 2. Factors that prolong the lifetime of a building

\subsection{Comparison of Existing Embodied Energy Calculation Plug-Ins}

Embodied energy that is related to the structure of a building can be visualized using two existing plug-ins that are developed to function with Rhinoceros (Rhino) and Grasshopper (GH) software, where they define a set of parameters that a designer can control to test the effect of different inputs. Each tool has its own set of parameters and algorithms adapted by the developers based on their interests and needs. The first is a prototype plug-in named "An Embodied Energy Optimization Tool" [23]. In this paper, for the convenience of use, this tool will be called "tool A". The graphical user interface of the tool is shown in Fig 3.The focus of its working prototype is on low-rise rectangular grid office buildings with steel structure and multi-objective optimization techniques. 


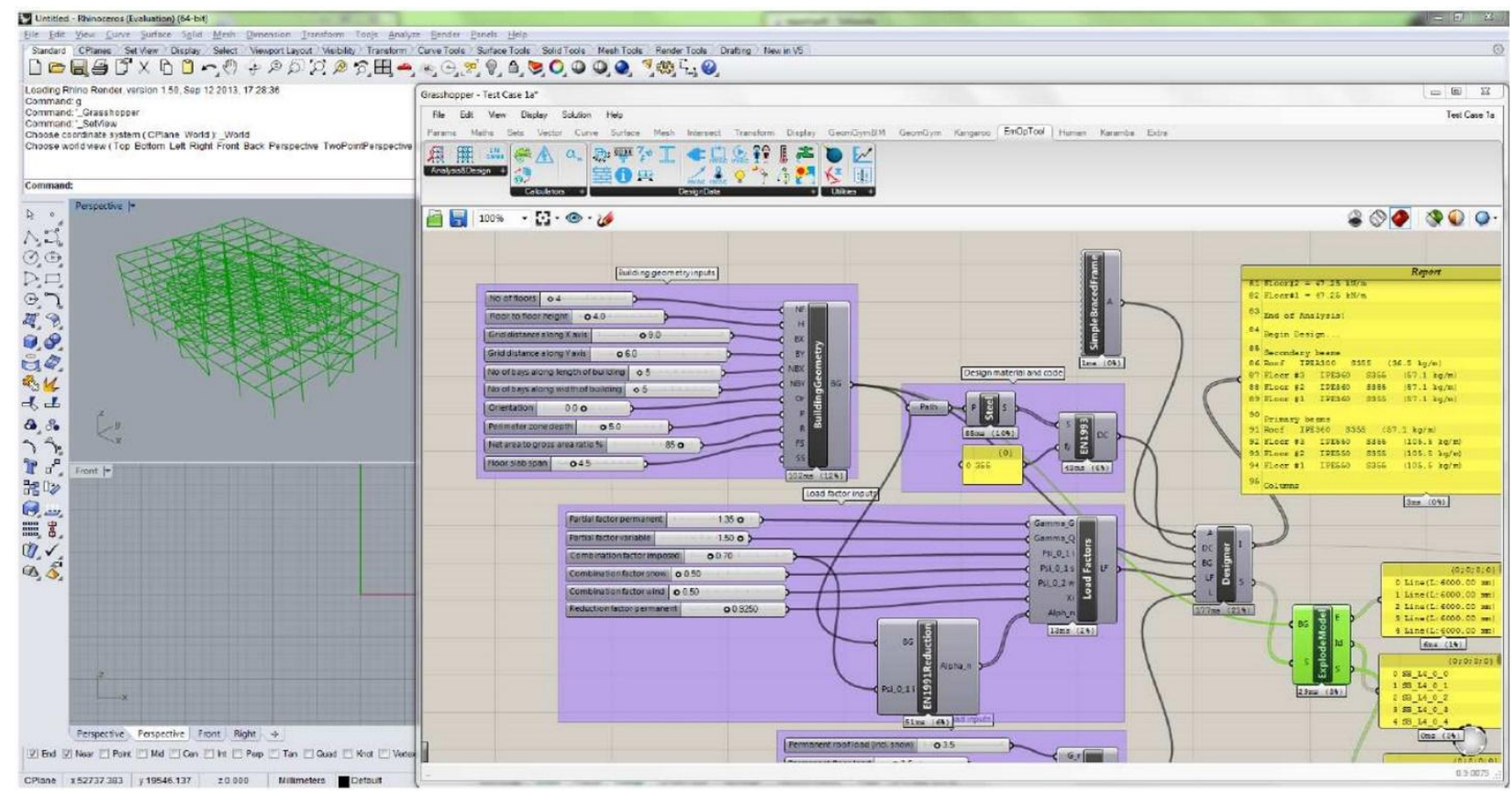

Figure 3. Graphical user interface of Embodied Energy Optimization Tool [23]

Tool A exports the final result into a third-party software for further analysis (Like Kangaroo or Geometry Gym). The tool is currently not available for public use, and the developers were contacted to help by providing more information on the use of this tool and its limitations. A parametric computational framework based on sustainability was set for tool A where it is possible to add new parameters, whether related to sustainability or others like the cost. Since the scope of features is large, the developers added restrictions to the framework so the tool could be developed and tested based on the availability of data. A set of assumptions (Table 1) were made on the design to measure the flexibility of the building and to calculate the embodied energy consumption of the lifecycle. Therefore, the developers propose further research on the tool in order to clarify the effect of these assumptions to help designers get more accurate calculations.

Table 1. Assumptions determined for the testing of tool A [23]

\begin{tabular}{|l|l|}
\hline $\begin{array}{l}\text { Building variable } \\
\text { (parameter) }\end{array}$ & Assumption \\
\hline Region & $\begin{array}{l}\text { Western Europe (Eurocode for } \\
\text { design) }\end{array}$ \\
\hline Building material & Steel \\
\hline Building function & Office use \\
\hline $\begin{array}{l}\text { Life-cycle analysis } \\
\text { aspect }\end{array}$ & $\begin{array}{l}\text { Energy efficiency and carbon } \\
\text { emissions }\end{array}$ \\
\hline Structural system & $\begin{array}{l}\text { Low to medium rise braced frame in } \\
\text { steel, diagonal wind bracings for }\end{array}$ \\
\hline
\end{tabular}

\begin{tabular}{|l|l|}
\hline & horizontal bracings \\
\hline $\begin{array}{l}\text { Beam column } \\
\text { connections }\end{array}$ & Pinned or hinged \\
\hline Façade and Roof & $\begin{array}{l}\text { Replaced during the life of the } \\
\text { building }\end{array}$ \\
\hline
\end{tabular}

The developers of tool A also suggest further development in the tool by conducting additional studies to identify and understand different types of structures, and to reach better optimization algorithms, analysis and design methods, user interface and visualizations, energy calculations, and database management systems [23]. It could also be modified to include calculations related to embodied energy in the finishing material. Moreover, tool A operates under the framework of Rhino and Grasshopper, and the results are not linked to a BIM software. Certain modifications in the user interface would be required to link tool A to a third-party BIM software or if it is to be published as a stand-alone software.

The second tool is the "Carbon Calculator", a part of the "TTtoolbox" plug-in [24]. In this paper, for the convenience of use, this tool will be called "tool B". This tool compares the variations in the structural elements that can contribute to a low EE in the building. In addition, the tool combines the data with the Inventory of Carbon and energy created by the University of Bath [25]. This allows the tool to calculate and visualize the amount of EE and embodied carbon (Figure 4) for any design configuration during the conceptual design stage in real time. 


\section{DESIGN PARAMETERS}
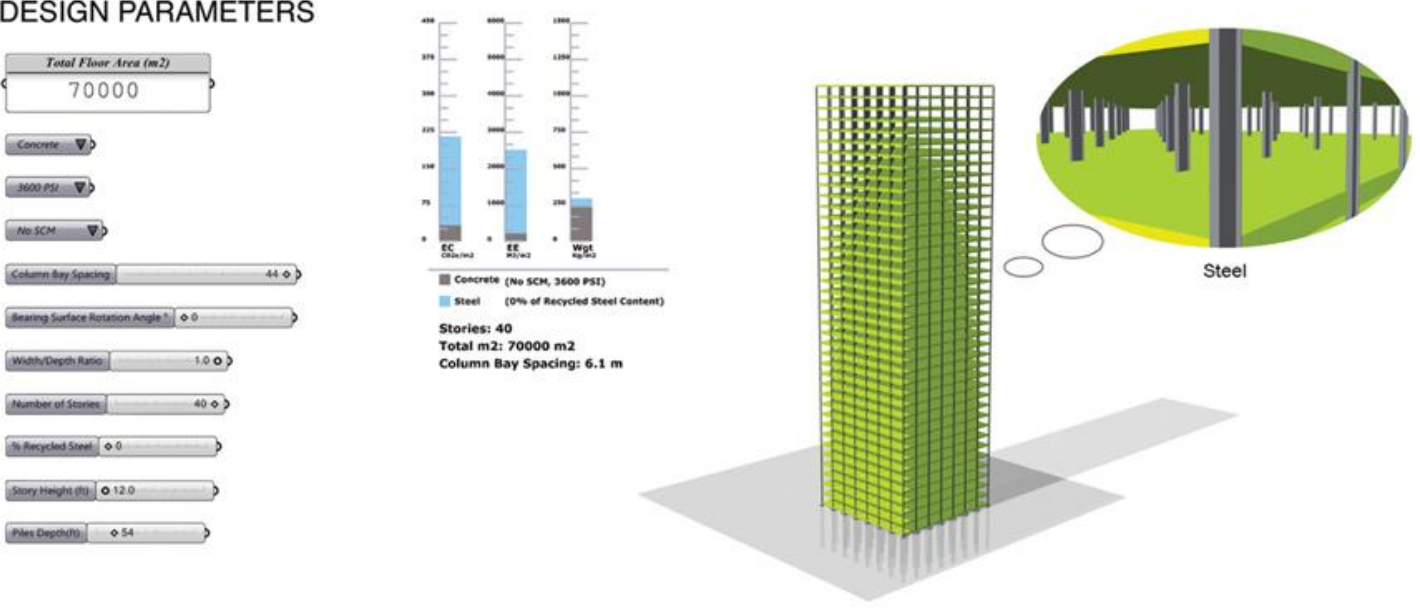

Figure 4. Graphical user interface of TTtoolbox Carbon Calculator [29]

Tool B is also a plug-in that works with GH and Rhino. Upon contacting the developer, it was indicated that tool $\mathrm{B}$ is an inhouse tool specific for the use of the developing office since it uses copyrighted algorithms. However, the developer provided a brief explanation for the use of this tool. It mainly deals with calculating the structural loading of the building, then calculating the structural member size. This leads to the calculation of the volume of material. The volume of material, in return, is multiplied by the amount of embodied carbon per unit volume, then the total is summed up to give the value of the embodied energy in the building. The variations in the input data can be visualized on a live model, and additional results can be seen in three bar graphs that display the embodied carbon, embodied energy, and the weight of the material (Figure 4). The user can add his input in the following parameters: total floor area, material for the structure, PSI (pressure per square inch), column bay spacing, bearing surface rotation angle, width/depth ration, number of floors, percentage of recycled steel, floor height, and piles' depth. The limitations of tool B are related to its scope in calculating the EE of the structural system only. Moreover, tool B does not provide neither an option to choose the type of building nor a visual display of the results to be compared with benchmark values for energy performance of buildings.

Upon comparing both available tools, it can be noted that both have limited their framework of calculations to the design of the structure of the building, whereas tool A features more flexibility in including additional parameters to its interface.
Both tools do not show any direct link to a BIM software like Revit that would allow making use of the data they provide to enhance the building design. Linking these tools to BIM software that is more widely used will help make this information available to more designers. In addition, both tools are not available for public use. Based on that comparison, a new tool can be developed. This new tool might be incorporated into those existing tools, or might help further develop them if they were made available for public.

\subsection{Main features of the EE Calculation Tool}

An accurate calculation of embodied energy includes the EE in the structural system and the finishing material. The structural system EE can be provided from tools similar to the ones discussed above. This research designs a new tool to calculate the embodied energy and embodied carbon of the finishing material of the building, specifically the material used in the façade. The same tool can be used for finishing material in the floors and ceilings, but due to time limitations only the façade material will be discussed. The tool also calculates the minimum (MinEE) and maximum (MaxEE) embodied energy value of each material. In order to help the designer compare design alternatives, the tool also provides the cost of each alterative. Hence the designer can make decisions on the tradeoff in options to remain within a preset cost margin. 


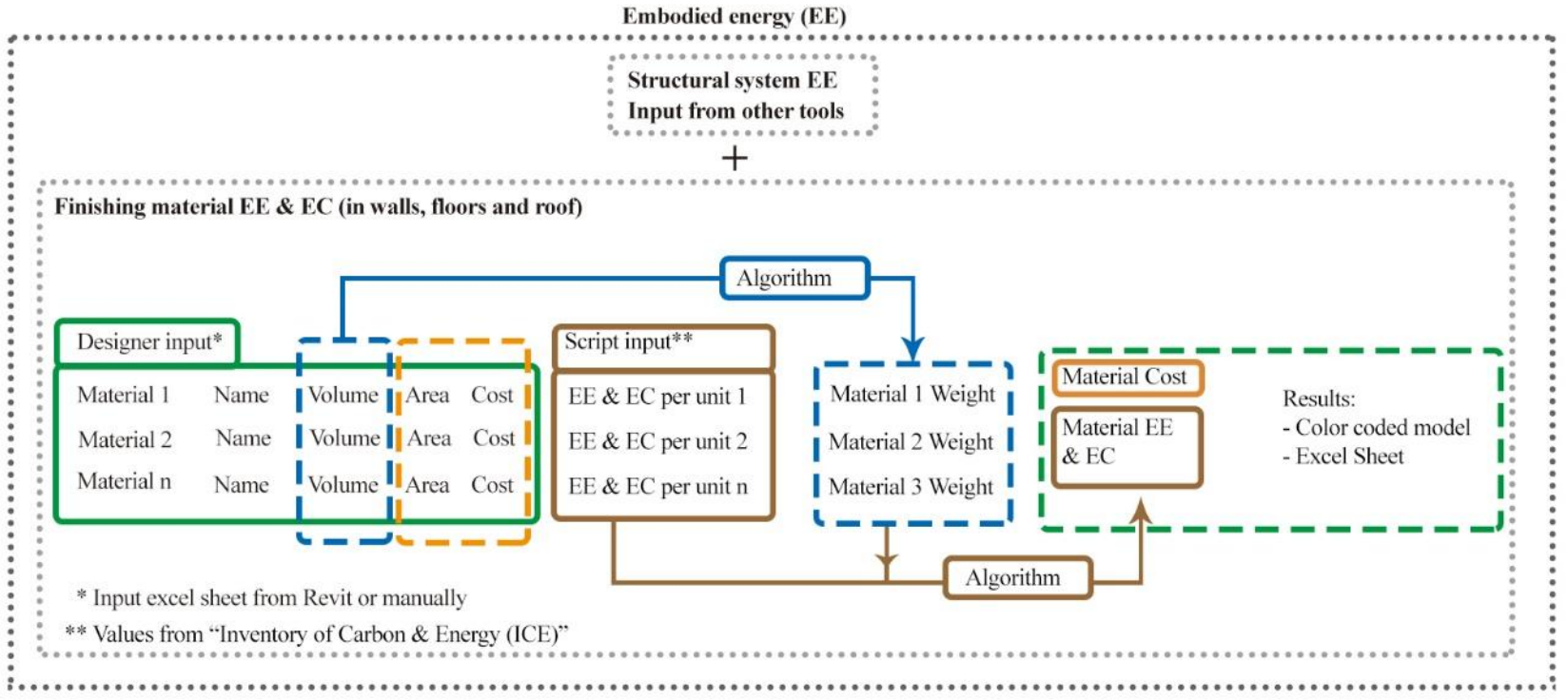

Figure 5. Embodied energy calculation tool framework

The diagram in Figure 5 shows the framework of the EE calculation tool developed in this research. The input data provided by the designer can be either added manually, or imported from an excel sheet that Revit can provide. "gHowl" (a plug-in for GH) can help import the excel sheet data into Grasshopper. The designer can be working on Revit or Rhino for his conceptual design stage, the method of data input will differ according to the software used. The tool would use the input of the material volume to provide the embodied energy value for each material based on data collected from the Inventory of Carbon and Energy (ICE) developed by the University of Bath in the UK [25] since the literature indicates that it is the most accurate source available now. The values used in the ICE depend on the material weight; hence, an algorithm to calculate the material weight from volume is added to the tool. The final $\mathrm{EE}$ values will be visualized individually and as a total on a colored model to help designers visualize the areas in the façade that need further changes for the reduction of EE. Moreover, the cost will be provided as a text to assess the effect of changes on the overall cost of the building design.

\subsection{The operating environment of the calculation tool}

The EE calculation tool is available as an example GH file within a parametric framework to give it flexibility. It functions with a main excel sheet prepared by the author that can be edited according to the users' need. A screenshot of the final graphical user interface (GUI) is provided in the figure below (Fig 6). The tool is adaptable to including various kinds of structures, building codes, building material, and analysis methods. In addition, the parametric framework of the tool gives it a flexibility in providing output data that can be used in various operations that the user might require

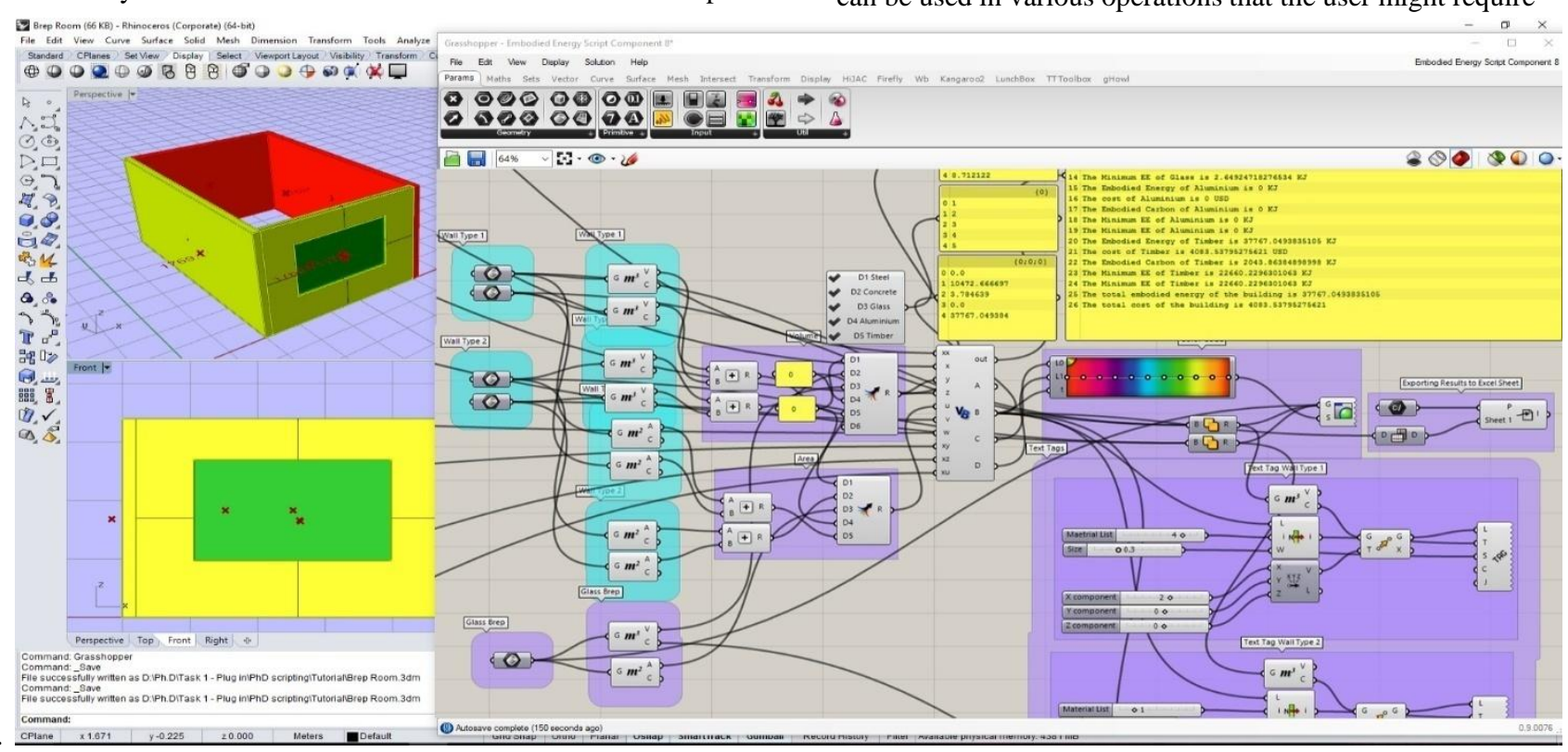

Figure 6. GUI of the EE calculation tool

\subsection{Testing and validation}


The EE calculation tool contains five main features (The EE, EC, MinEE, MaxEE, Cost) that require testing to confirm the functionality of the tool along with a validation of these test results. The validation can be performed through manual calculations; therefore, a simple case study (Figure 7) is chosen for testing: a $50 \mathrm{~m} 2$ room with one glass window and two different wall types. The external walls are assumed to be of concrete masonry units, and the internal walls are light gypsum partitions. The room model is created in Rhino and not imported directly from Revit since the available plug-ins that import Revit models to Rhino only import the geometry. The embodied energy and embodied carbon depend on the variation in the amount of material used among other factors, so the geometry alone will not be enough to give an accurate result. The room model provides the area and volume of the material used, and these parameters are added as input to the tool script. The output of the script is used to assign a proper color to the walls and window according to the calculated data, while adding the text values of the EE to each object. The results were confirmed with manual calculations and showed that the tool functions based on simple algorithms and can be helpful in the early design stages. The tool also provides the user with an output excel sheet report of the calculated data. It should be noted that the tool was tested successfully on a simple case study with a limited amount of details. Additional testing is required to help enhance the interface and to help include further parameters in the input data.

Case Study: $50 \mathrm{~m}^{2}$ room

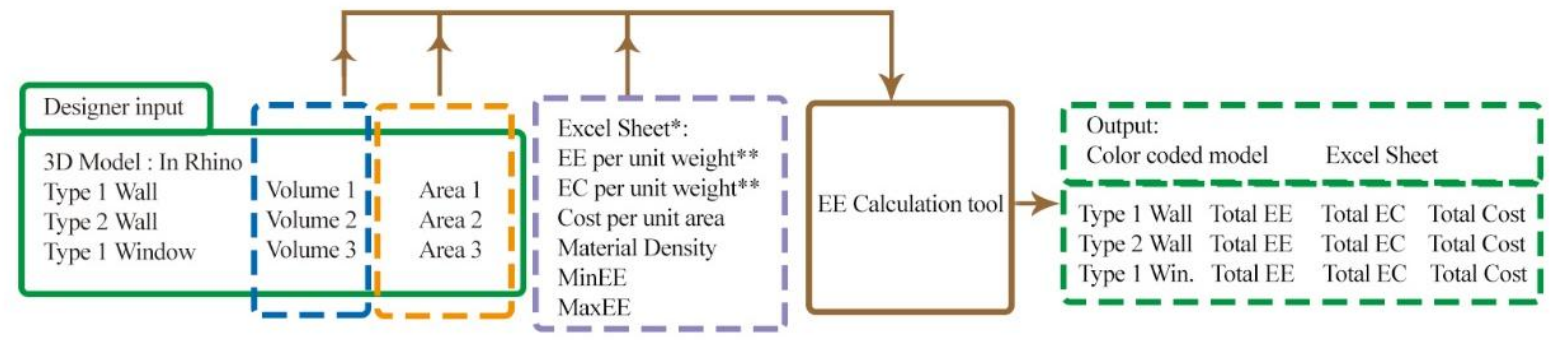

* Input excel sheet from Revit or manually

** Values from "Inventory of Carbon \& Energy (ICE)"

Figure 7. Case Study using the EE calculation tool

\section{DISCUSSION}

The EE calculation tool gives a visual model of the EE and $\mathrm{EC}$ in the building façades in the conceptual design stage while keeping an eye on the cost. EE calculations are typically done with the help of spreadsheets that are not understood by all users, while their results are hard to integrate in other software. The EE calculation tool gives an example of how these calculations can be simplified. The tool calculations are based on the ICE values which are derived in the UK. Ideally, each region should have its own inventory since the life-cycle assessment calculations depend highly on the geographic location of the site and the availability of local material. Also, the ICE depends on the "cradle to gate" analysis system and complies with the UK building codes which are factors that may also change depending on the building region. Users can modify these values by editing the original excel sheet set by the author. In addition, the tested case studies all involved a single-layer wall. To add multi-layered walls in the calculations, the user should either calculate the average EE of the designed walls, or the building model should assign a separate geometry for each material layer. These solutions could add to the complexity of the tool; an alternate solution would be to develop a plug-in that works on exporting a layered model from Revit.

The tool also features a limited number of material that can be used in the façade, but the list can be expanded to include additional material by adding the relevant data in the same order presented in the adjoining input excel sheet. Moreover, the tool interface can be incorporated with the existing tools that calculate the EE related to the structure, and when incorporating the operating energy to give a full energy simulation of the building. This tool was developed within a very limited time frame. Future research will focus on presenting the tool in the form of a plug-in that can export data to BIM software since they are more abundant in use, and might become a design requirement by the government in upcoming years. When compared to the existing tools presented earlier in the research, the developed EE calculation tool can be considered as complementary, and it can be an additional feature to the existing tools since it gives results concerning a different parameter within the calculation of embodied energy. Tools A and B calculate the embodied energy within the structure of the building, while the EE calculation tool gives the result within the façade material. Moreover, the EE calculation tool gives the cost of material used in the façade with an immediate visualization of the result giving the designer the option of making changes while keeping an eye on the overall budget of the project. The input of data can be done by either the use of an excel sheet or a model giving the designer the flexibility to use the most convenient feature. Finally, the algorithms and source data of the EE calculation tool are easily accessed which allows it to be open sourced so it can benefit from changes suggested by users worldwide.

\section{CONCLUSION}

Calculations to evaluate the embodied energy in a building can help enhance the energy performance of a building. Most buildings are designed to minimize the operating energy as it is easier to predict and evaluate in early stages of design. Most tools that are available for the evaluation of energy work on one type of energy in a building (either the operating or the embodied energy). They are also mostly used in later stages in the design process and they are performed by sustainability experts, who in most cases are not involved in early stages of design. The embodied energy calculation tool provides regular designers with a simple tool to perform calculations related to the embodied energy without the need for an external consultant. This will help the designer make more environmentally conscious decisions without adding to the cost of the design (in most design cases the owner is not 
willing to pay the additional costs required for sustainable studies). Incorporating the output of the provided tool with existing BIM software can also help the designer enhance the design based on the results, and carry on from the conceptual stage of the design. The tool assists in determining the lifecycle embodied energy consumption and the embodied carbon in the facades of a building while taking the cost into consideration; hence, it allows the comparison and studying of various design alternatives, materials, and products to choose the most appropriate alternative that suits the project requirements.

The main framework of the tool is parametric since it is easier to make it as an open source tool for further development. The tool helps in the evaluation of one factor (out of seven) that affects the values of embodied energy in a building. As a future scope for the tool, it can be used as an example to create additional calculation techniques for the other factors. Any variable or algorithm used in this tool can be modified, removed, or added easily without affecting its functionality, which gives it a lot of potential to develop into finer calculation methods with the progress in the design process, so the designer can customize its calculation methods as needed. Moreover, the tool could include other details that the designer might need to assess the design while considering alternatives such as fire engineering. Once the tool is further developed and tested in a variety of projects it can be redesigned in a different framework that can be used as a direct plug-in for BIM software. It would be best to continue working on the code and parameters of the tool until it can be directly incorporated with a software like Revit without the need for a third-party software to make proper conversions for the EE calculations or the produced model. Finally, when the tool is programmed as a plug-in it can be available for commercial use for designers to use it freely.

\section{ACKNOWLEDGMENTS}

Many thanks go to the Ph.D. program supervisors who helped in the writing and review of the paper. An appreciation goes to Engineer Bilal Maassarani and for Majida Mabsout for their insights that helped develop this research.

\section{REFERENCES}

[1] Spence RMulligan H. Sustainable development and the construction industry. Habitat International. 1995;19(3):279-292.

[2] Holtzhausen H. Embodied energy and its impact on architectural decisions. WIT Transactions on Ecology and the Environment. 2007;102:377-385.

[3] Horvath A. Construction materials and the environment. Annu. Rev. Environ. Resour.. 2004 Nov 21;29:181-204.

[4] Curwell S, Cooper I. The implications of urban sustainability. Building Research \& Information. 1998 Jan 1;26(1):17-28.

[5] Uher TE. Absolute indicators of sustainable construction. In Proceedings of COBRA 1999 (pp. 243-253).

[6] D. Palit. Green Buildings. An occasional Paper Prepared for World Energy Efficiency Association, 2004.

[7] Huovila P. Buildings and climate change. Paris, France: United Nations Environment Programme, Sustainable Consumption and Production Branch; 2007.

[8] Anderson J. Embodied Carbon \& EPDs [Internet]. greenspec. 2016 [cited 11 October 2016]. Available from:

http://www.greenspec.co.uk/buildingdesign/embodied-energy/

[9] Ding GK. The development of a multi-criteria approach for the measurement of sustainable performance for built projects and facilities (Doctoral dissertation).

[10] Crowther P. Design for disassembly to recover embodied energy.

[11] Sartori I, Hestnes AG. Energy use in the life cycle of conventional and low-energy buildings: A review article. Energy and buildings. 2007 Mar 31;39(3):249-57.

[12] Keoleian GA, Blanchard S, Reppe P. Life- cycle energy, costs, and strategies for improving a single- family house. Journal of Industrial Ecology. 2000 Apr 1;4(2):135-56

[13] Hannon B, Stein RG, Segal BZ, Serber D. Energy and labor in the construction sector. Science. 1978 Nov 24;202(4370):837-47.

[14] Nässén J, Holmberg J, Wadeskog A, Nyman M. Direct and indirect energy use and carbon emissions in the production phase of buildings: an input-output analysis. Energy. 2007 Sep 30;32(9):1593-602.

[15] Langston YL, Langston CA. Reliability of building embodied energy modelling: an analysis of 30 Melbourne case studies. Construction Management and Economics. 2008 Feb 1;26(2):147-60.

[16] Miller A. Embodied Energy-A life-cycle of transportation energy embodied in construction materials. InCOBRA 2001, Proceedings of the RICS Foundation Construction and Building Research Conference 2001.

[17] Basbagill J, Flager F, Lepech M, Fischer M. Application of life-cycle assessment to early stage building design for reduced embodied environmental impacts. Building and Environment. 2013 Feb 28;60:81-92.

[18] Gluch P, Baumann H. The life cycle costing (LCC) approach: a conceptual discussion of its usefulness for environmental decision-making. Building and environment. 2004 May 31;39(5):571-80.

[19] Schlueter A, Thesseling F. Building information model based energy/exergy performance assessment in early design stages. Automation in construction. 2009 Mar $31 ; 18(2): 153-63$

[20] Ariyaratne CI, Moncaster AM. Stand-alone calculation tools are not the answer to embodied carbon assessment. Energy Procedia. 2014 Dec 31;62:150-9.

[21] Motawa I, Carter K. Sustainable BIM-based evaluation of buildings. Procedia-Social and Behavioral Sciences. 2013 Mar 29;74:419-28.

[22] Capper G, Matthews J, Lockley S. Incorporating embodied energy in the BIM process.

[23] Koonath Surendran S, Rolvink A, Coenders JL, Welleman JW, Den Hollander JP, Hoekstra Bonnema B. Embodied energy optimization tool. InProceedings of the International Association for Shell and Spatial Structures (IASS) Symposium" Future Visions", Amsterdam, The Netherlands, 17-20 August 20152015 Dec 31. KIVI.

[24] Embodied Carbon and Energy Efficiency Tool | CORE studio [Internet]. Core.thorntontomasetti.com. 2016 
[cited 11 October 2016]. Available from: http://core.thorntontomasetti.com/embodied-carbonefficiency-tool/

[25] Hammond G, Jones C, Lowrie F, Tse P. Inventory of carbon \& energy: ICE. Bath: Sustainable Energy Research Team, Department of Mechanical Engineering, University of Bath; 2008.

[26] Lebel GG, Kane H. Sustainable development: a guide to our common future; the report of the WCED.
[27] Foster JS, Greeno R, Harington R. Structure and fabric. Pearson Education; 2007.

[28] Tool F. Ontwerptool voor de beoordeling van constructieve alternatieven op duurzaamheid (Doctoral dissertation, TU Delft, Delft University of Technology).

[29] CORE Studio. Carbon Calculator Interface [Internet]. 2016 [cited 2 November 2016]. Available from: http://core.thorntontomasetti.com/carbon-calculator/ 